\title{
Communicating and Sharing in the Semantic Web: An Examination of Social Media Risks, Consequences, and Attitudinal Awareness
}

\author{
Nicole Buzzetto-More, Robert Johnson, and Muna Elobaid \\ University of Maryland Eastern Shore, Princess Anne, MD, USA
}

\author{
Nabuzzetto-more@umes.edu rajohnson@umes.edu \\ meelobaid@umes.edu
}

\begin{abstract}
Empowered by and tethered to ubiquitous technologies, the current generation of youth yearns for opportunities to engage in self-expression and information sharing online with personal disclosure no longer governed by concepts of propriety and privacy. This raises issues about the unsafe online activities of teens and young adults. The following paper presents the findings of a study examining the social networking activities of undergraduate students and also highlights a program to increase awareness of the dangers and safe practices when using and communicating, via social media. According to the survey results, young adults practice risky social networking site (SNS) behaviors with most having experienced at least one negative consequence. Further, females were more likely than males to engage in oversharing as well as to have experienced negative consequences. Finally, results of a post-treatment survey found that a targeted program that includes flyers, posters, YouTube videos, handouts, and in-class information sessions conducted at a Mid-Atlantic Historically Black College or University (HBCU) increased student awareness of the dangers of social media as well as positively influenced students to practice more prudent online behaviors.
\end{abstract}

Keywords: Cyber awareness, Cyber Safety, Facebook, Internet Safety, Negative Consequences of Social Media, Oversharing, Privacy, Social Media, Social Media Safety, Web-Safety

\section{Background}

Social media come in many forms from bookmarking services like Delicious, Pinterest, and BibSonomy, to 3D Virtual Worlds like Second life, professional networking systems like LinkedIn, Blogging tools like Blogger, microblogging tools like Twitter, collaborative content creation tools such as Wikipedia or Wikispaces, photo sharing services like Flickr and Instagram, profile and friend/social management systems like Facebook and MySpace, video sharing services like

Material published as part of this publication, either on-line or in print, is copyrighted by the Informing Science Institute. Permission to make digital or paper copy of part or all of these works for personal or classroom use is granted without fee provided that the copies are not made or distributed for profit or commercial advantage AND that copies 1) bear this notice in full and 2) give the full citation on the first page. It is permissible to abstract these works so long as credit is given. To copy in all other cases or to republish or to post on a server or to redistribute to lists requires specific permission and payment of a fee. Contact Publisher@InformingScience.org to request redistribution permission.
YouTube, and micro-video blogging services like Vine. Inherent to all is the concept of user generated content, sharing, and social commentary, which have been found to encourage social expression and participation (Buzzetto-More, 2014a). Further, they have all been found particularly effective at appealing to digital natives (Buzzetto-More, 2013). 
The major tools and services are best expressed by the infographic shown in Figure 1: Social Media Landscape 2013, which is provided courtesy of Fred Cavazza (2013)

(www.FredCavazza.net,), and which categorizes social media tools into the areas of publishing, sharing, networking, and discussing and places Facebook, Twitter, and Google + at the epicenter.

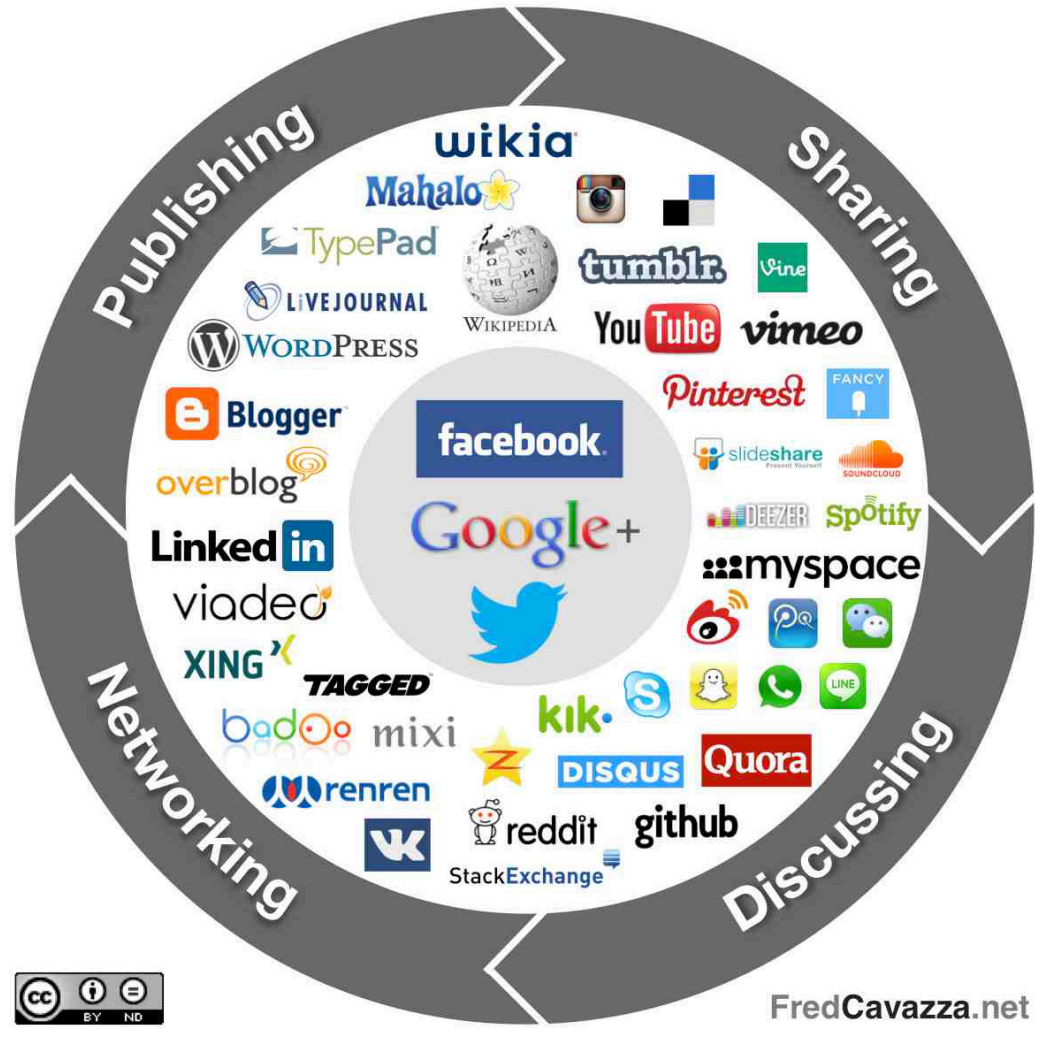

Figure 1: Social Media Landscape

A study (Duggan \& Smith, 2013) reported that as of September 2013, 73\% of all online adults use social networking sites with $90 \%$ of adults ages $18-29$ being social media users. Additional findings included in the report are as follows:

- Social networking sites are increasingly used to keep up with social ties,

- Facebook users are more trusting than others,

- Facebook revives "dormant" relationships,

- The majority of Facebook users check the site multiple times per day,

- Most social media users are active across multiple platforms (Duggan \& Smith, 2013).

Today's college students are habituated to using technologies that have changed practices of identity formation and self-expression. This raises issues about the unsafe activities of teens and young adults who frequently fall victim to invasion of privacy, unauthorized disclosure of personal information, inappropriate self-disclosure, internet addiction, cyber-bullying, stalking, scams and hoaxes, identity theft, and defamation (Buzzetto-More, 2012a). More specifically, when Facebook use is considered, the following are among the most significant dangers for young adults (Buzzetto-More, 2014b):

- Social media can harm a user's image by presenting them in a less than desirable and/or unprofessional light. This can stop a young adult from obtaining a job or internship. 
- Services like Facebook keep everything forever. Whether something has been deleted, untagged, hidden, removed, Facebook keeps a record of it. Click on a profile, upload a photo, update your status, change your profile, Facebook remembers.

- Social media sites encourage users to enter and share as much as possible. However this data is exposed to cyber criminals. Further, the social networking systems themselves are not secure from hacking.

- Social media is plagued by scams, hoaxes, computer viruses, identity theft, malware, and click jacking.

- ALL social media sell user information. Also, once a user approves a website or app to interact with Facebook or another social network, all activity will be automatically shared with Facebook, whether the user is logged in or not.

- When Facebook saves photos, they don't just make a copy of the original, but instead they make multiple copies to use in various ways. And each photo that is uploaded to Facebook carries with it the metadata that digital cameras include with each image. On some cameras, such as the iPhone, metadata can also include the precise GPS location of where the photo was taken.

- Bad behavior on social networks is cause for termination by many employers. Complaining about one's job and/or sharing work information violates many employer acceptable use policies. Something as simple as sharing a sexist image or racy joke can also violate company policy. Further, most human resource managers consider a potential employees social media behavior.

- It is easy, and common, for people to hijack social media accounts and post on other's behalf. Often these posts are particularly damaging. Further, cyber bullying remains a very real concern on social media.

- Social media can invite crime. When users post updates about where they are or "check in" they may be providing information and an incentive to would be criminals.

This study seeks to enhance the body of literature that focuses on young adults and risky online behaviors. More specifically, the paper explores the risky social media activities of students attending a Mid-Atlantic HBCU with an additional investigation into the negative consequences experienced. The research procedures included distribution of a detailed survey that examined the communication patterns and social media behaviors of undergraduate management students, followed by the delivery of an awareness campaign that included course level lectures, posters, and videos, and concluded with a post-treatment survey that examined the impact and efficacy of the awareness. Six hypotheses were developed and explored as part of this study and were as follows:

- H1: College students practice risky social networking behaviors

- H2: Students have experienced negative consequences as a result of SNS use

- H3: Females are more likely than males to overshare information via social media

- H4: Females are more likely than males to have experienced negative consequences as a result of SNS use

- H5: Individuals who had a social media profile before the age of 16 are more likely to have had a negative experience than those who opened their first profile after age 16.

- H6 A targeted program can increase awareness of SNS safety

\section{Literature Review}

Today's youth use social media to build and affirm relationships by engaging in self-expression and information sharing online (Buzzetto-More, 2014a). This raises issues about the unsafe activities of teens and young adults. In particular, during times of heightened emotions people have 
been shown to be more likely to express private or emotional information (Berger, 2011) that Cohen (2012) refers to as having engendered the current "culture of oversharing".

In a 2011 Pew survey about the future impact of the Web, most technology experts and stakeholders participating agreed that the Millennial generation is changing the way society considers personal disclosure and information-sharing via their use of social media (Hampton, Sessions, Ranie, \& Purcell, 2011). Further, the report found that many experts surveyed hoped that society will become forgiving of those whose youthful mistakes remain on display in social media in perpetuity.

A number of researchers have postulated that youth identity formation in the modern age is best examined within the self-authored identities available on Facebook (Ryan \& Xenos, 2011). The way personality specific traits impact Facebook use, or non-use, was investigated by Ryan and Xenos (2011) who based their findings on a sample of 1158 Facebook users and 166 non-users who responded to questionnaires that included aspects of the Big Five personality inventory. According to the findings, Facebook users tend to be more extroverted, more narcissistic, and exhibit a lower level of conscientiousness than non-users and, concurrently, seem to experience a higher level of social loneliness than non-users.

Nadkarni and Hofmann (2012) introduced a model to explain Facebook user's motivation supported by two basic needs: (1) the need of affiliation and belongingness, and (2) the need of selfpresentation. They explained that demographic and cultural factors are mostly related to the need of affiliation, while personality traits like neuroticism, narcissism, timidity, and self-esteem correlate with the need of self-presentation.

Enhancement of one's online identity, which in turn impacts self-esteem, has consistently been shown to be a motivator for social media use that in turn impacts self disclosure. A study by Muise, Christofides, \& Desmarais (2009) concluded that Facebook is a forum where information is readily shared by users because of the site's influence on a user's need for popularity. The correlation between social media disclosure and self-worth was further explored by Rui \& Stefanone (2013) who found that the drive for self-worth via public evaluations increased the intensity of social media posts and photo sharing.

Studies have found that teenagers have few concerns about privacy, and this disinterest leads to unsafe behavior on SNS (Vanderhoven, Schellens, \&Valcke, 2013). Further, during times of heightened emotions people are more likely to share highly private or emotional information (Berger, 2011) with an expectation of acceptance to their emotionally laden postings (Wizenburg, 2012). Cohen (2012) explains that this culture of oversharing has created a phenomenon known as "status anxiety" that feeds on the insecurities of individuals.

According to Weitzenkorn (2013) the Web may seem safe and social media services relatively innocuous, but oversharing on social media can result in real-life negative consequences impacting almost all areas of a person's life. More specifically, a devastating influence can occur on an individual's reputation, relationships, finances, and even physical well-being.

A study of 1,000 online individuals conducted by Retrovo (2010), asked people if they had ever posted anything online about themselves that they regretted. According to the findings $(32 \%)$ of respondents admitted to having posted something online that they regretted. When age was specifically examined, respondents under the age of 25 were found more likely to have regretful posts than their over 25 counterparts.

Vanderhoven, Schellens, and Valcke (2013) explained that privacy attitudes also need to be taken into account if we want to decrease the amount of unsafe behavior on social networking sites. Further, they explained that there was almost no research on the impact of school education on privacy attitudes or actual safe behavior on SNS. As a result, they conducted a survey study of 
636 teenagers examining their attitudes towards privacy on SNS. According to the findings, rather low levels for privacy care on SNS were found. Especially younger teenagers and boys were found to exhibit no concern about privacy issues on SNS.

In a large-scale study conducted by the Pew Center, Lenhart, Madden, Smith, Purcell, Zickher, and Ranie (2011) examined the experience and behaviors of teenagers on social networking sites. A summary of their findings include that:

- $88 \%$ of social media-using teens have witnessed other people be mean or cruel on SNS;

- $15 \%$ of teen social media users have experienced harassment in the past 12 months;

- $41 \%$ of teens who use social media have had at least one negative outcome;

- $25 \%$ of social media using teens have had an experience on a social network site that resulted in a face-to-face argument or confrontation with someone;

- $22 \%$ have had an experience that ended their friendship with someone;

- $13 \%$ have had an experience that caused a problem with their parents;

- $8 \%$ have had a physical fight with someone because of something on a SNS;

- $30 \%$ of participating teens reports sharing one of their online passwords with a friend, boyfriend, or girlfriend.

A 2013 follow-up Pew study (Madden, Lenhart, Cortesi, Gasser, Duggan, Smith, \& Beaton, 2013) found that teens had become even more forthcoming with personal information than they had been in previous studies as well as highly likely to manipulate their profile and timeline content in order to garner the maximum number of likes.. Additionally, the study found an increase in teen Twitter use as well as the following:

- $59 \%$ of respondent have deleted or edited something that they posted in the past,

- $53 \%$ of respondent have deleted comments from others on their profile or account,

- $45 \%$ of respondent have removed their name from photos that have been tagged to identify them,

- $31 \%$ of respondent have deleted or deactivated an entire profile or account,

- $19 \%$ of respondent have posted updates, comments, photos, or videos that they later regretted sharing,

- Girls are more likely than boys to delete friends from their network ( $82 \%$ vs. $66 \%)$ and block people ( $67 \%$ vs. $48 \%)$,

- African-American teens that use social media are more likely than white teens to say that they post fake information to their profiles (39\% vs. $21 \%$ ),

- Online girls are more than twice as likely as boys to report contact from someone they did not know that made them feel scared or uncomfortable (24\% vs. $10 \%)$.

Additional studies have shown that Facebook abuse shows a significant positive correlation with mental health deterioration, mainly with anxiety, stress, and pathological depression of users (Hughes, Rowe, Batey, \& Lee, 2012.) Even more concerning is that individuals suffering from social anxiety or depressed people are more prone to engage in online communication and relationships, instead of engaging in face-to-face interactions, which in turn propagates the vicious cycle of loneliness and isolation (Sheldon, 2008).

An article that focused on online disclosure as portrayed in Facebook profiles, which examined hundreds of students at a north-eastern university found that women were more likely to disclose personal and relationship information about themselves on social networking sites like Facebook, whereas men were more likely to share information on activities they're engaged in or opinions on politics and sports (Kolek \& Saunders, 2008). It also found that as age increases, selfdisclosure on social networking sites decreases. Further, in a recent study published in the Jour- 
nal of Social Media and Society (Sheldon, 2013) women were found to disclose to their exclusive face-to-face friends and exclusive Facebook friends more than men.

In an article that sought to raise awareness of oversharing via social media, Weitzenkorn (2013) advised SNS users not to disclose political views, to be careful what they "like" since the record is maintained and is searchable, avoid posting when angry or upset, change profile settings to private, avoid commenting on a controversial issue, disable the ability to be tagged in photos, change passwords monthly, and remove personal information from social media services. Weitzenkorn's advice is for users to search themselves on all major search engines, delete undesirable/questionable posts and photos, and lockdown accounts with the most private settings possible.

What is the best way to increase awareness and thus decrease risky online behaviors? Vanderhoven et al. (2013) explored the impact that school education has on both privacy care and the safety of teenagers' behavior on SNS. According to the findings, education conducted in schools has a positive impact on increasing students concern and awareness of issues of privacy, which in turn results in less risky behaviors conducted on social networking sites. They explained that more effort is needed in schools as the topic remains inadequately and sporadically addressed in most curricula. It has been found that the implementation of the topic of online safety is inconsistent despite the fact that a variety of educational packages about safety and security in SNS have been developed.

\section{Methodology}

\section{Participants}

Founded in 1886, the University of Maryland Eastern Shore (UMES) is a Historically Black, 1890 land grant institution. It is a member of the University system of the state of Maryland, the U.S. state with the highest population of African Americans. UMES primarily serves first generation, low income, and minority learners. The student population is approximately 4500 , with a student body that is approximately $78 \%$ African-American, $9.6 \%$ white, $1.4 \%$ Hispanic, and $11 \%$ international, primarily coming from the continent of Africa and/or from the Caribbean region. The gender distribution of the University is $64 \%$ female and $36 \%$ male. The freshmen-tosophomore retention rate is $71 \%$, and the graduation rate is $41 \%$. The school was ranked in the top 25 among HBCUs in 2014 and the acceptance rate for applying students is $62.4 \%$ with the majority of students coming from the Mid-Atlantic region, more specifically the Baltimore and Washington D.C. urban centers.

By conducting this study at an HBCU, it provides research on a population that has previously not received sufficient focus. Whereas a handful of studies have been conducted at majority institutions and a number with K-12 students, this is the first study of this magnitude that has been conducted at Historically Black Colleges and/or Universities. Further, examinations conducted at Historically Black Colleges and/or Universities are important because the critical mass of African American college students can be found at HBCUs, which represent less than $3 \%$ of U.S. colleges and universities but produce $25 \%$ of our nations Black college graduates as well as the preponderance of African American doctoral degree recipients (Adams, 2012).

\section{Materials}

All students enrolled at the University of Maryland Eastern Shore are required to complete a general education sequence of courses that include a discipline specific/major related freshmen professional development course, a computer concepts course, and professional communications course. A study conducted in the spring of 2014 at a Mid-Atlantic minority serving institution sought to examine the perceptions and risky behaviors of students with respect to social network- 
ing services. In order to examine student perceptions, a survey was developed and delivered using the Zoomerang/Survey Monkey system. Pre-testing was done in order to inform the survey design process. The developed survey was comprised of a combination of dichotomous, Likert-scaled, ordinal, ratio, short answer, and contingency questions. The survey was evaluated by several content and methodological experts in order to examine bias, vagueness, or potential semantic problems. Finally, the survey was pilot tested prior to implementation in order to test the efficacy of the research methodology. It was then modified accordingly prior to distribution to potential participants.

An educational campaign that included custom developed posters, a prepared YouTube video, handouts, and live presentation/informational in-class sessions was launched. The poster used during the campaign were hung in public areas across campus, placed on bulletin boards where the Department of Business, Management and Accounting is housed, hung in the classrooms where the live in-class informational sessions were delivered, and posted adjacent to the campus cafeteria. Two of the custom posters created as part of this program are presented as Figures 2 and 3.

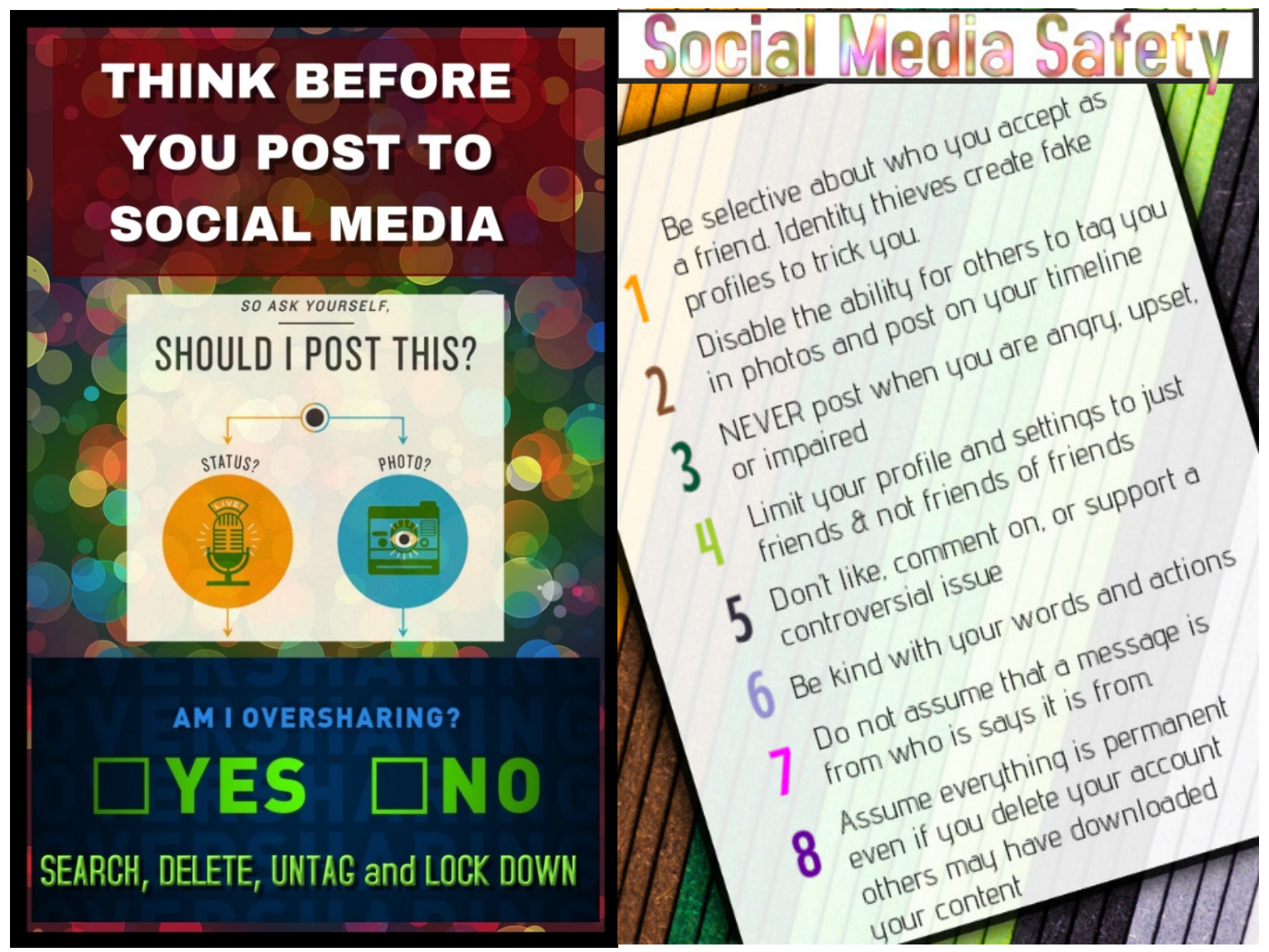

Figures 2 \& 3. Posters

A video presentation was created and posted to YouTube in order to support the educational awareness campaign. The video titled Social Media Risks and Safety can be found at http://youtu.be/zIFqNXmqiVE. Additionally, aspects of the awareness campaign included the delivery of live informational in-class sessions and the distribution of factual handouts.

Post treatment an online survey was distributed to the students who had completed the first survey as well as who had participated in the educational awareness campaign. The purpose of the 
survey was to measure changes in opinions as well as student perceptions of the efficacy and effectiveness of the awareness campaign.

\section{Procedures}

During the data collection process, students who were enrolled in several sections of targeted general education service courses received an automated email with a personalized link to the online survey. Using the email invitation collector component of Survey Monkey, a unique link was generated for each recipient. While individual responses were anonymous, this linked each response directly to an email address which was used to track completions and not specific responses. Additionally, students were given the option of opting out of the study.

The automated email message was not the only point of contact. Response rates were tracked and following the initial invitation, two reminders were sent to non-respondents in two week intervals following the initial invitation.

The survey was distributed to 414 potential participants and completed by 253 respondents, representing a response rate greater than $60 \%$. During the data analysis process the raw data was exported from the Survey Monkey system and imported into Microsoft Excel where descriptive statistics such as mean, skewness, standard deviation, and confidence level were examined and frequency distributions in the form of counts and percentages considered. In order to consider the hypotheses appropriate testing measures were performed and included examination of frequency distribution and/or descriptive statistics (as appropriate) as well as conduction of crosstabulations and T-tests where fitting.

Following the distribution and collection of the survey, an educational campaign that included design and development of posters hung across campus as well as in program delivery classrooms, development and use of a custom YouTube video, handouts, and in-class delivered informational sessions was launched.

Post treatment a second online survey was distributed to the 225 students who had participated in phase 1 resulting in 99 completed surveys and a $44 \%$ response rate. The raw data was exported from the distribution system and imported into Microsoft Excel where descriptive statistics such as mean, skewness, standard deviation, and confidence level were examined and frequency distributions in the form of counts and percentages considered. Additionally, comparisons of student responses to questions pre and post treatment were made.

Six hypotheses were developed and explored as part of this study. These hypotheses focused on the risky behaviors and negative consequences of social media use, the differences between male and female respondents, the impact of age on negative experiences, and the success or failure of a program delivered to increase awareness of SNS safety.

- Hypothesis 1 considers a range of activities considered risky such as oversharing via social media, whether users allow others to tag them in posts or post on their profile, and profile settings that make their profile available to either everyone or friends of friends.

- Hypothesis 2 focuses on negative outcomes. It is addressed by considering responses to a series of five Likert scaled agreement questions:

- I have experienced at least one negative outcome as a result of social media use

- I have posted or tweeted something on a social media site that I later regretted

- I had a friend post an embarrassing or inappropriate picture of me

- I have had someone post something about me that I found embarrassing

I I have gotten into an argument with someone via social media. 
- Hypothesis 3 considered whether females are more likely than males to overshare by comparing means by gender and via a two-tailed T-test. More specifically, it compared the responses of males and females to the Likert scaled statement.

- On at least one occasion, I have overshared information via social media

- Hypothesis 4 considered whether females are more likely than males to experience a negative consequence as a result of social media use by comparing means by gender and via a two-tailed T-test. More specifically, it compared the responses of males and females to the Likert scaled question.

- I have experienced at least one negative outcome as a result of social media use

- Hypothesis 5 examined whether individuals who had a social media profile before the age of 16 are more likely to have had a negative experience than those who opened their first profile after age 16. It was based on responses to a dichotomous question that asked individuals if they had their first social media profile before the age of 16 and responses to the Likert scaled statement

- I have experienced at least one negative outcome as a result of social media use

- Hypothesis 6 examined the effectiveness of the targeted social media safety program and campaign. It was based on an evaluation of students' responses to the following Likert scaled statements included in the post treatment survey.

- As a result of the campaign, I am more aware of the dangers of social media use.

- As a result of the campaign, I am more aware of how to be safe when using social media.

- As a result of the campaign, I plan to be more cautious when using social media.

$\circ$ As a result of the campaign, I plan to make my social media accounts more secure.

- Universities should educate students about the potential dangers of social media use.

Additionally, several questions purposely included on the pre and post survey were compared in order to examine changes in perception pre-treatment verses post-treatment.

\section{Results}

In total $96 \%$ of respondents were between the ages of 18 and 29 with $90 \%$ of respondents specifically between 18 and 22 . With respect to gender distribution, $57 \%$ of respondents were female and $43 \%$ of respondents were male. When distribution by degree progress was considered, the majority of students were either freshmen $(35 \%)$ or sophomore $(28.1 \%)$ standing, with fewer juniors $(21.3 \%)$ and seniors $(15 \%)$.

A dichotomous question was used in order to explore participants' prior exposure to and use of social networking sites with $92 \%$ of respondents reporting that they have a profile on a social networking site. Taking a contingency approach, those who currently have profiles on social networking site were asked how likely they are to use social networking sites in a typical week most respondents $(>50 \%)$ said "extremely likely". These results are represented in Table 1.

Participants were asked how many of their "friends" on social networking websites have they met in person. According to the results, only $14.5 \%$ of respondents have met all of their online friends in person with rest $(85.5 \%)$ not having met in person all of their online friends. 


\section{Table 1: Frequency of Social Media Use}

\begin{tabular}{lrc}
\hline In a typical week, how likely are you to use social networking websites? & \\
\hline Answer Options & $\begin{array}{c}\text { Response } \\
\text { Percent }\end{array}$ & $\begin{array}{c}\text { Response } \\
\text { Count }\end{array}$ \\
Extremely likely & $57 \%$ & 128 \\
\hline Likely & $28.7 \%$ & 67 \\
Moderately likely & $12 \%$ & 28 \\
Slightly likely & $2 \%$ & 5 \\
Not at all likely & $1.7 \%$ & 4 \\
\hline & answered question & $\mathbf{2 3 3}$ \\
\hline
\end{tabular}

Participants were asked to estimate how much of their time on social networking sites is spent posting things about themselves with $16 \%$ estimating that all of their time is spent dedicated to self-promotion, $19 \%$ reporting that most of their time is dedicated to self-promotion, $23 \%$ estimating that self-promotion represents half of their social networking activities, $36 \%$ saying some of their time is self-promotion based, and 6\% saying that they spend no time on social media posting anything about themselves.

All participants were asked what age they joined their first social networking site, $61 \%$ responded that they were under the age of $15(>15)$ and $33 \%$ said that they were between the ages of 16 and 18. The full response distribution to this question is represented in Table 2.

\section{Table 2: Age That Participants Started Using Social Media}

\begin{tabular}{lcc}
\hline At what age did you start using social networking services & \\
Answer Options & $\begin{array}{c}\text { Response } \\
\text { Percent }\end{array}$ & $\begin{array}{c}\text { Response } \\
\text { Count }\end{array}$ \\
15 or under & $60.6 \%$ & 151 \\
$\mathbf{1 6 - 1 8}$ & $32.5 \%$ & 81 \\
$\mathbf{1 9 - 2 3}$ & $3.6 \%$ & 9 \\
$\mathbf{2 4 - 3 0}$ & $2.8 \%$ & 7 \\
$\mathbf{3 1 - 4 0}$ & $0.0 \%$ & 0 \\
$\mathbf{4 1 - 5 0}$ & $0.4 \%$ & 1 \\
$\mathbf{5 0}$ & $0.0 \%$ & 0 \\
\hline I have never joined a social networking site & & 3 \\
& answered question & $\mathbf{2 4 9}$ \\
\hline
\end{tabular}


The following section will present the results from the six hypotheses that were considered as part of this study. In order to consider each hypothesis, appropriate testing measures were performed and included examination of frequency distribution and/or descriptive statistics (as appropriate) as well as conduction of crosstabulations and t-tests where fitting. In the following section, each hypothesis will be discussed individually, and in turn.

\section{A. Hypothesis 1: College students practice risky social networking behaviors}

In order to explore $\mathrm{H}_{1}$ : "College students practice risky social networking behaviors", participants were asked to respond to several five-point Likert-scaled statements. According to the results, the participants have been guilty of oversharing via social media with a mean of 3.06, venting frustrations via social media with a mean of 3.01, posting something that they would not want their parents to see with a mean of 2.79 , and posting something that they would not want a potential employer to see with a mean of 3.02. The results from these Likert-scaled question are presented in Table 3.

\begin{tabular}{|l|l|l|l|l|}
\hline \multicolumn{5}{|c|}{ Table 3: Risky Online Behaviors } \\
\hline & $\begin{array}{c}\text { I have been } \\
\text { guilty of over- } \\
\text { sharing via } \\
\text { social media }\end{array}$ & $\begin{array}{c}\text { I can't help it, } \\
\text { sometimes, I } \\
\text { vent my frus- } \\
\text { trations via } \\
\text { social media }\end{array}$ & $\begin{array}{c}\text { I have posted pic- } \\
\text { tures, updates, } \\
\text { comments, etcet- } \\
\text { era that I would } \\
\text { not want my par- } \\
\text { ents to see }\end{array}$ & $\begin{array}{c}\text { I have posted } \\
\text { something I } \\
\text { would not want a } \\
\text { potential employ- } \\
\text { er to see }\end{array}$ \\
\hline Mean & 3.06 & 3.01 & 2.79 & 3.02 \\
\hline Skew & -0.0351 & -0.0879 & 0.1059 & -0.1097 \\
\hline $\begin{array}{l}\text { Standard De- } \\
\text { viation }\end{array}$ & 1.341763 & 1.3324 & 1.281268 & 1.374 \\
\hline $\begin{array}{l}\text { Confidence @ } \\
\mathbf{9 5 \%}\end{array}$ & 0.0741409 & 0.0736239 & 0.0707982 & 0.0759327 \\
\hline Mode & 4 & 4 & 3 & 4 \\
\hline
\end{tabular}

In order to further explore Hypothesis one, a series of questions examined participants' SNS profile settings; none of the participants had a closed profile that is not available for viewing, $24 \%$ said their profile is open to everyone, $23 \%$ said it is available to friends and friends of friends (FOF), $25 \%$ said just friends, and $26 \%$ said "no idea I never changed the default" which at the time of this survey meant that there profile was open. Additionally all respondents allow others to post on their timeline, see what is on their timeline, tag them in posts or photos, and allow others to see posts where they have been tagged.

These results are represented in detail in Table 4. 
Table 4: Student Profile Settings

\begin{tabular}{|l|c|c|c|c|c|}
\hline Answer Options & $\begin{array}{c}\text { No Idea I never } \\
\text { changed from } \\
\text { the default }\end{array}$ & Everyone & $\begin{array}{c}\text { Friends } \\
\text { and } \\
\text { Friends of } \\
\text { Friends }\end{array}$ & Friends & $\begin{array}{c}\text { Nobody/ } \\
\text { Not Al- } \\
\text { lowed }\end{array}$ \\
\hline My profile is open & $26.6 \%$ & $24.2 \%$ & $23.6 \%$ & $25.6 \%$ & $0 \%$ \\
\hline Who can post on your timeline? & $20 \%$ & $23.6 \%$ & $31.3 \%$ & $25.3 \%$ & $0 \%$ \\
\hline $\begin{array}{l}\text { Who can see things on your time- } \\
\text { line? }\end{array}$ & $17.5 \%$ & $37.7 \%$ & $18.5 \%$ & $26.1 \%$ & $0 \%$ \\
\hline $\begin{array}{l}\text { Who can see posts you've been } \\
\text { tagged in on your timeline? }\end{array}$ & $13.7 \%$ & $27 \%$ & $29.1 \%$ & $30 \%$ & $0 \%$ \\
\hline $\begin{array}{l}\text { Who can tag you in posts or pho- } \\
\text { tos? }\end{array}$ & $15.5 \%$ & $23.4 \%$ & $24.2 \%$ & $36.9 \%$ & $0 \%$ \\
\hline
\end{tabular}

\section{B. Hypothesis 2: Students have experienced negative consequences as a result of social media use}

Several negative outcomes were explored in order to test $\mathrm{H}_{2}$ "Students have experienced negative consequences as a result of social media use" in the form of five-point Likert-scaled questions; $60 \%$ of respondents said that they have had at least one negative consequence as a result of their use of social media. Further, 58\% have been upset by something someone posted or tweeted; $44 \%$ have posted or tweeted something that they later regretted; $41 \%$ had a friend has post an embarrassing/inappropriate picture of them; $40 \%$ have gotten into an argument via social media; $36 \%$ have had someone post something about them that they found embarrassing; and 39\% have received a nasty comment from a post or tweet that they had made. The results for this series of Likert-scaled questions are represented in Table 5.

\begin{tabular}{|l|c|c|c|c|c|}
\hline \multicolumn{5}{c}{ Table 5: Negative Consequences } \\
\hline $\begin{array}{l}\text { I have had at } \\
\text { least one nega- } \\
\text { tive conse- } \\
\text { quence/experien } \\
\text { ce as a result of } \\
\text { using social me- } \\
\text { dia }\end{array}$ & 3.33 & 1.27661 & 0.0705413 & -0.4649 & Mode \\
\hline $\begin{array}{l}\text { I have been up- } \\
\text { set by something } \\
\text { someone posted } \\
\text { or tweeted }\end{array}$ & 3.32 & 1.326104 & 0.0732757 & -0.5238 & 4 \\
\hline $\begin{array}{l}\text { I have post- } \\
\text { ed/tweeted } \\
\text { something I later } \\
\text { regretted }\end{array}$ & 3.01 & 1.361934 & 0.0752555 & -0.1486 & \\
\hline
\end{tabular}




\begin{tabular}{|l|l|l|l|l|l|}
\hline $\begin{array}{l}\text { I have had a } \\
\text { friend(s) post an } \\
\text { embarrassing } \\
\text { picture of me on } \\
\text { Facebook or } \\
\text { another social } \\
\text { networking site }\end{array}$ & 3.01 & 1.253958 & 0.0692892 & -0.1032 & 4 \\
\hline $\begin{array}{l}\text { I have gotten } \\
\text { into an argu- } \\
\text { ment with some- } \\
\text { one through } \\
\begin{array}{l}\text { Twitter, Face- } \\
\text { book, or another } \\
\text { social network- } \\
\text { ing site }\end{array}\end{array} \quad 2.95$ & 1.302267 & 0.0719585 & -0.0460 & 4 \\
\hline $\begin{array}{l}\text { I have had an- } \\
\text { other person } \\
\text { post something } \\
\text { about me that I } \\
\text { found embar- } \\
\text { rassing }\end{array}$ & 2.88 & 1.314206 & 0.0726182 & 0.0549 & \\
\hline $\begin{array}{l}\text { Ihave received } \\
\text { a nasty comment } \\
\text { to a post/tweet I } \\
\text { made }\end{array}$ & 2.85 & 1.312778 & 0.0725393 & 0.0301 & \\
\hline
\end{tabular}

\section{Hypothesis 3: Females are more likely than males to overshare information via social media}

In order to explore whether females are more likely than males to overshare, the mean responses to the statement "On at least one occasion, I have overshared information via social media" was considered and the results were compared by gender. Additionally, a Two-tailed T-Test set to .05 was performed in order to test, and subsequently affirm, $\mathrm{H}_{3}$ : "Females are more likely than males to overshare information via social media". These results are presented in Table 6.

\section{Table 6: Gender and Oversharing}

MALE

FEMALE

\begin{tabular}{l|c|c|c|}
\multicolumn{1}{c|}{ Mean } & \multicolumn{1}{c}{ Stdv. } & Mean & \multicolumn{1}{c}{ Stdv. } \\
\hline & 1.447048 & 3.17 & 1.187603 \\
\hline & & \\
Comparison of Means & & \\
T-TestCI@95\% & & \\
$P=.00161$ & \\
\hline
\end{tabular}




\section{Hypothesis 4: Females are more likely than males to have experienced negative consequences as a result of SNS use}

In order to explore whether females are more likely than males to have experienced negative consequences as a result of social media use, the mean responses for each gender were to the statement "I have had at least one negative consequence/experience as a result of using social media" were compared. Additionally, a Two-tailed T-Test set to .05 was performed in order to test, $\mathrm{H}_{4}$ : "Females are more likely than males to have experienced negative consequences as a result of SNS use". These results are presented in Table 7.

Table 7: Gender and Negative Consequences

\begin{tabular}{lcccc}
\hline & MALE & & FEMALE & \\
& Mean & Stdv. & Mean & Stdv. \\
$\begin{array}{l}\text { I have had at least one neg- } \\
\text { ative conse- } \\
\text { quence/experience as a re- } \\
\text { sult of using social media }\end{array}$ & 2.86 & 1.313367 & 3.60 & 1.092811 \\
\hline
\end{tabular}

Comparison of Means

T-TestCI@95\%

$P=.05$

\section{E. Hypothesis 5: Individuals who had a social media profile before the age of 16 are more likely to have had a negative experience than those who opened their first profile after age 16.}

In order to explore $\mathrm{H}_{5}$ : Individuals who had a social media profile before the age of 16 are more likely to have had a negative experience than those who opened their first profile after age 16 , participants were asked whether they had their first social media profile before age 16 . The means of those who said that they had their first profile before age 16 were compared to those who responded that they did not with respect to agreement to the Likert-scaled statement "I have had at least one negative consequence/experience as a result of using social media". According to the responses those who had a social media profile $<16$ had a mean of 3.41 compared to a 3.0 for those $>16$. Additionally, a Two-tailed T-Test set to .05 was performed which resulted in a $P$ value of greater than $.05(\mathrm{P}=.96)$. The full results are presented in Table 8 .

\begin{tabular}{|l|c|c|c|c|}
\hline \multicolumn{4}{|c|}{ Table 8: Age and Negative Consequences } \\
\hline $\begin{array}{l}\text { I had my first social media } \\
\text { profile before age 16 }\end{array}$ & \multicolumn{2}{|c|}{ YES=70\% } & \multicolumn{2}{c|}{ NO=30\% } \\
\hline & Mean & Stdv. & Mean & Stdv. \\
\hline $\begin{array}{l}\text { I have had at least one nega- } \\
\text { tive consequence/experience } \\
\text { as a result of using social } \\
\text { media }\end{array}$ & 3.41 & 1.29445 & 3.00 & 1.162 \\
\hline & & & \\
\hline & Comparison of Means & \\
\hline & T-Test CI @ 95\% \\
\cline { 2 - 5 } & $P=.96$ & \\
\cline { 2 - 4 }
\end{tabular}




\section{F. Hypothesis 6: A targeted program can increase awareness of SNS safety}

An educational campaign that included posters, a custom YouTube video, handouts, and presentation/informational sessions was launched. Post treatment an online survey was distributed to the 225 students who had participated in phase 1 resulting in 99 completed surveys and a $44 \%$ response rate and used to test $\mathrm{H}_{6}$ : "A targeted program can increase awareness of social media safety." According the findings, $90 \%$ agreed that as a result of the campaign they were more aware of the dangers of SNS and how to be safe when using SNS (91\%), plan to be more cautious $(92 \%)$, and make their SNS accounts more secure (86\%). Finally, respondents agreed that Universities should educate students about the potential dangers of SNS use $(88 \%)$ and safe use practices $(89 \%)$. The descriptive data for these responses are presented in Table 9.

Table 9: Student Perceptions of the Awareness Campaign

\begin{tabular}{|c|c|c|c|}
\hline & $\begin{array}{l}\text { As a result of the fly- } \\
\text { ers, lecture, and/or } \\
\text { other information I } \\
\text { have received I am } \\
\text { more aware of the } \\
\text { potential dangers of } \\
\text { social media use }\end{array}$ & $\begin{array}{l}\text { I am now aware of } \\
\text { how to be safe when } \\
\text { using social media }\end{array}$ & $\begin{array}{l}\text { I plan on making a } \\
\text { greater effort to be } \\
\text { cautious when post- } \\
\text { ing to social media }\end{array}$ \\
\hline Mean & 4.381443299 & 4.367346939 & 4.434343434 \\
\hline Standard dev & 0.994184119 & 0.912544365 & 0.847103301 \\
\hline Confidence & 0.195838158 & 0.17975645 & 0.166865621 \\
\hline \multirow[t]{2}{*}{ Skewness } & -2.066951495 & -2.131040527 & -2.20576935 \\
\hline & $\begin{array}{l}\text { I plan on making (or } \\
\text { have recently made) } \\
\text { my Facebook account } \\
\text { more secure }\end{array}$ & $\begin{array}{l}\text { Universities should } \\
\text { make an effort to ed- } \\
\text { ucate students about } \\
\text { the potential dangers } \\
\text { of social media use }\end{array}$ & $\begin{array}{l}\text { Universities should } \\
\text { make an effort to } \\
\text { educate students } \\
\text { about social media } \\
\text { safety }\end{array}$ \\
\hline Mean & 4.375 & 4.295918367 & 4.323232323 \\
\hline Standard dev & 0.943119125 & 0.943880821 & 0.912814473 \\
\hline Confidence & 0.185779182 & 0.185929223 & 0.179809656 \\
\hline Skewness & -1.8213382 & -1.755329595 & -1.842019857 \\
\hline
\end{tabular}

Additionally, questions included on the pre and post survey were compared and there was a measured increase in the belief that employers are likely to review SNS activities for potential candidates (from $51 \%$ pre-treatment to $86 \%$ post-treatment); and the belief that undesirable activities can hurt the ability for a candidate to find employment (from $63 \%$ pre-treatment to $91 \%$ post-treatment). These results are presented in Table 10. 


\begin{tabular}{|l|c|c|}
\hline \multicolumn{3}{|c|}{ Table 10: Pre and Post Treatment Comparison } \\
\hline & $\begin{array}{c}\text { Pre- } \\
\text { Treatment }\end{array}$ & $\begin{array}{c}\text { Post Treat- } \\
\text { ment }\end{array}$ \\
\hline $\begin{array}{l}\text { I think potential employers are likely to look at my social } \\
\text { networking activities }\end{array}$ & 3.54 & 4.41 \\
\hline $\begin{array}{l}\text { Social networking activities that are undesirable to a po- } \\
\text { tential employer can hurt a candidates ability to obtain } \\
\text { employment }\end{array}$ & 3.75 & 4.38 \\
\hline
\end{tabular}

\section{Discussion}

The current study under consideration discusses student perceptions and behaviors focused on the risky social media activities of students, negative consequences experienced as a result of social media use, differences in perception based on gender, and the impact of an awareness campaign. The analyzed data and hypotheses testing was presented in the results section. In the discussion section, the meaningfulness of the results of the tested hypotheses will be explored and related to the existing body of literature.

Hypothesis 1: "College students practice risky social networking behaviors" represents the first time that this topic has been explored through an examination of students attending a Historically Black College or University (HBCU). The findings in this study supported Hypothesis 1 and are consistent with what has been reported in the literature through such studies as those published by Cohen (2012); Lenhart et al., (2011), Vanderhoven et al. (2013), and Wizenburg (2012) who also reported that young adults practice a number of risky behaviors via social media.

Hypothesis 2: "Students have experienced negative consequences as a result of social media use" was affirmed by the analyses of the data collected as part of this study. Additionally, these findings are similar to what has been reported by in the literature by Lenhart et al., (2011), Retrovo (2010), and Weitzenkom (2013) who have reported on the dangers and damages that can coincide with social media use. Since this study was conducted at a HBCU, the findings provide initial evidence to suggest that race has no bearing on whether a college student experiences negative consequences as a result of social media use.

Hypotheses 3 and 4 examined gender differences with respect to social media use. Hypothesis 3 postulated that "Females are more likely than males to overshare via social media" and was supported by the results. Further, the findings are consistent with what has been reported in the literature (Kolek, \& Saunders, 2008; Sheldon, 2013) who found that college-age females are more forthcoming with their self-disclosure via social media than males. Hypothesis 4, which examined whether "Females are more likely than males to have experienced negative consequences as a result of SNS use" was supported and is consistent with what has been reported in studies conducted by Lenhart et al. (2011) and Madden et al. (2013).

Hypothesis 5 explored the role of age by testing whether "Individuals who had a social media profile before the age of 16 are more likely to have had a negative experience than those who opened their first profile after age 16." This is an area that has received limited attention in the literature. As a result of the analyses conducted, hypothesis five was not affirmed, which is inconsistent with such findings as those reported by Retrovo (2010) which found that when age was specifically examined respondents under the age of 25 were found more likely to have regretful posts than their over 25 counterparts. As a result, of the limited focus on this topic in the literature as well as the inconsistent findings across reports, more research into this particular topic is needed. 
Hypothesis 6 examined the efficacy of an awareness program by testing "A targeted program can increase awareness of SNS safety." This is an area which has received very little focus in the literature As a result of the data analyzed, hypothesis 6 was affirmed with results consistent with what has been reported by Vanderhoven et al. (2013)

\section{Limitations}

The most significant limitation of this study is that it focused solely on business students attending a single small-sized U.S. public minority-serving university. In order to remedy the shortfalls inherent in this research, the researcher is looking to replicate this study at additional institutions of higher education.

\section{Conclusion}

Social media is making Marshall McCluhan's image of a global village (McCluhan, 1964) become a reality as the social software movement promotes virtual spaces which emerge as zones for information-sharing, collaboration, exploration, and community formation and extension (Branch, 2006). Social networking tools are engendering a redefinition of our concepts of community (Thomas, 2007). They are expanding the diffusion of new ideas and are serving as mechanisms for change agents and opinion leaders (Smith, 2009). If we take a technologically deterministic approach, social networking will continue to shape society and culture by permanently altering concepts of privacy, information exchange, friendship, self-expression, teaching and learning, and public discourse.

The pervasiveness of mobile technologies, combined with the ease of access to multiple communication networks, have globalized communication exchanges in a way that is unprecedented. Compelled to receive constant information updates from their ever expanding peer networks, the average person has been transformed to a hyper-connected habitué of social media (BuzzettoMore, 2012b). Permanently tethered to their electronic devices they traverse the social media landscape seeking engagement and enlightenment all the while sharing virtually all aspects of their daily lives with personal disclosure no longer governed by traditional privacy norms. According to the survey results presented in this paper, young adults practice risky social networking site (SNS) behaviors with most having experienced at least one negative consequence. Further, females were more likely than males to engage in oversharing as well as to have experienced negative consequences. Finally, results of a post-treatment survey found that a targeted program that includes flyers, posters, YouTube videos, handouts, and in-class information sessions conducted at a Mid-Atlantic HBCU increased student awareness of the dangers of social media as well as positively influenced students to practice more prudent online behaviors.

The results of this study provide further evidence regarding the pitfalls and perils faced by today's Net-generation of students with respect to the use of social networking services. Additionally, this paper illustrates the efficacy of a social media safety and awareness program initiated with undergraduate learners. It is advised that additional universities consider adopting similar curricula and further exploration into effective methodological practices and approaches to delivering such programs be encouraged. 


\section{References}

Adams, A. (2012, September 25). HBCUs, which play a vital role in minority education, need more funding. Washington Post.

Berger, J. (2011). Arousal increases social transmission of information, Psychological Science, 22(7), 891893.

Branch, P. (2006). Footprints in the digital sand. Independent School, 65(4), 12.

Buzzetto-More, N. (2012a). Understanding social media. In C. Cheal, J. Coughlin, \& S. Moore (Eds.), Transformation in teaching: Social media strategies in higher education (pp. 1-18). Santa Rosa: CA, Informing Science Press.

Buzzetto-More, N. (2012b). Social Networking in Undergraduate Education. Interdisciplinary Journal of Information, Knowledge, and Management. 7(1). 63-90.

Buzzetto-More, N. (2013). The use of YouTube to engage digital natives: Student preferences and perceptions in online and hybrid courses. Proceedings of the 19th Annual SLOAN Consortium International Conference on Online Learning. November 20-22, 2013. Orlando, Florida.

Buzzetto-More, N. (2014a). An examination of undergraduate student's perceptions and predilections of the use of YouTube in the teaching and learning process. Interdisciplinary Journal of E-Learning and Learning Objects, 10(1) 17-32. Retrieved from http://www.ijello.org/Volume10/IJELLOv10p017032Buzzetto0437.pdf

Buzzetto-More, N. (2014b). Social media risks and safety. YouTube Video available at: http://youtu.be/zIFqNXmqiVE

Cavazza, F. (2013). Social media landscape 2013. Retrieved 8/22/14 from www.fredcavazza.net

Cohen, R. (2012, December 11). Time to tune out. New York Times, p. 1.

Duggan, M., \& Smith. A. (2013). Social media update 2013. Pew Research Internet Project. Retrieved 4/3/14 from http://www.pewinternet.org/2013/12/30/social-media-update-2013/

Hampton, K., Sessions, L., Rainie, L., \& Purcell, K. (2011). Social networking sites and our lives. PEW Research Internet Project. Retrieved 4/3/14 from: http://www.pewinternet.org/2011/06/16/socialnetworking-sites-and-our-lives/

Hughes, D., Rowe, M., Batey, M., \& Lee, A. (2012). A tale of two sites: Twitter vs. Facebook and the personality predictors of social media usage. Computers in Human Behavior, 28(2), 561-569.

Kolek, E. A., \& Saunders, D. (2008). Online disclosure: An empirical examination of undergraduate Facebook profiles. NASPA Journal, 45(1), 1-25.

Lenhart, A., Madden, M., Smith, A., Purcell, K., Zickuhr, K., \& Rainie, L. (2011). Teens, kindness and cruelty on social network sites: How American teens navigate the new world of "digital citizenship. Pew Internet \& American Life Project.

Madden, N., Lenhart, A., Cortesi, S., Gasser, U., Duggan, M., Smith, A., \& Beaton, M. (2013). Teens, social media, and privacy. Pew Research Internet Project. Published Report available at: http://www.pewinternet.org/2013/05/21/teens-social-media-and-privacy

McCluhan, M. (1964). Understanding media. New York, New York: Delacorte Presd.

Muise, A., Christofides, E., \& Desmarais, S. (2009). More Information than you ever wanted: Does Facebook bring out the green-eyed monster of jealousy? CyberPsychology and Behavior, 12(4). 441-444.

Nadkarni, A., \& Hofmann, S. (2012). Why do people use Facebook? Personality and Individual Differences, 52(3), 243-249.

Retrevo. (2010). Preserve your Facebook privacy, post cautiously. Retrieved 4/2/14 from http://www.retrevo.com/content/blog/2010/05/preserve-your-facebook-privacy-post-cautiously 
Ryan, T., \& Xenos, S. (2011). Who uses Facebook? An investigation into the relationship between the Big Five, shyness, narcissism, loneliness, and Facebook usage. Computers in Human Behavior, 27(5), 1658-1664.

Rui, J., \& Stefanone, M. A. (2013). Strategic image management online: Self-presentation, self-esteem and social network perspectives. Information, Communication \& Society, 16(8), 1286-1305.

Sheldon, P. (2008). The relationship between unwillingness-to-communicate and students' Facebook use. Journal of Media Psychology, 20, 67-75.

Sheldon, P. (2013). Examining gender differences in self-disclosure on Facebook versus face-to-face. The Journal of Social Media in Society, 2(1). Retrieved from http://thejsms.org/index.php/TSMRI/article/view/14

Smith, M. K. (2009). Social capital. The encyclopedia of informal education. Retrieved 5/10/2011 from www.infed.org/biblio/social_capital.htm

Thomas, J. (2007). Social networking sites' effect on relationships among college students. Retrieved $12 / 1 / 10$ from http://www.associatedcontent.com/article/393599/social_networking_sites_effect_on_relationships_pg 14.html?cat $=41$

Vanderhoven, E., Schellens, T., \& Valcke, M. (2013). Exploring the usefulness of school education about risks on social network sites: A survey study. Journal of Media Literacy Education, 5(1), 285-294.

Winzenburg, S. (2012). In the Facebook era, students tell you everything. Chronicle of Higher Education, $58(42), \mathrm{A} 26$.

Weitzenkorn, B. (2013). How to avoid the risks of social-media oversharing. Tech News Daily. Retrieved July 22, 2013 from http://www.technewsdaily.com/18545-social-media-oversharing.html

\section{Biographies}

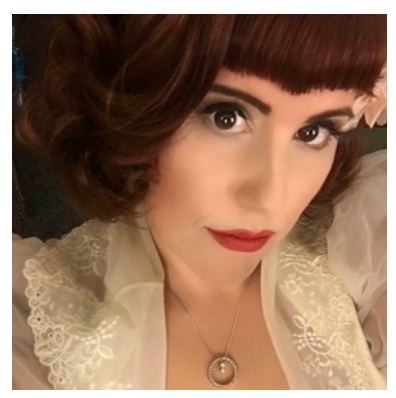

Dr. Nicole A. Buzzetto-More is a Professor, Program Coordinator, and the Assurance of Learning and Assessment Chair in the Department of Business at the University of Maryland Eastern Shore. She is also Director of the Maryland State Department of Education Program Affiliate for Business, Management, and Finance. She received doctorate and masters degrees in communications from Columbia University and earned a post doctorate in management and marketing from Tulane University. She also earned a masters degree from the College of New Rochelle and a bachelor's degree from Marist College. Dr. BuzzettoMore is a frequent invited presenter at conferences across the globe; is on the editorial board of several journals; has authored numerous publications; and has been recognized with awards from the American Distance Education Consortium, Global Digital Business Association, and the Informing Science Institute. She published two books in 2007, Principles of Effective Online Teaching and Advanced Principles of Effective ELearning. In 2010 her third book The E-Portfolio Paradigm: Informing, Educating, Assessing, and Managing with EPortfolios was published by the Informing Science Press. She has also published a number of chapters in edited volumes, including a 2012 contribution to the book Transformation in Teaching: Social Media Strategies in Higher Education. In 2013, she redesigned the official State completer programs for the Business, Management, and Finance (BMF) Pathways for the Maryland State Department of Education. Currently, she is involved in the redesign of the general education sequence for her university. 


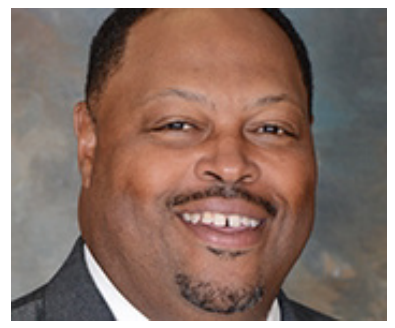

Dr. Robert Johnson is an Associate Professor and Chair of the Department of Mathematics and Computer Science at the University of Maryland Eastern Shore. Dr. Johnson has centered his professional efforts on identifying, securing, and establishing resources that create awareness and stimulate interests in the vast opportunities that exist in the Science, Technology, Engineering, and Mathematics (STEM) fields. He and a team of faculty members have secured over $\$ 3,000,000$ in federal, state, and industry funds to aid students in completing financial obligations related to collegiate study, gateway course completion, completing intense research projects, and matriculation to graduation.

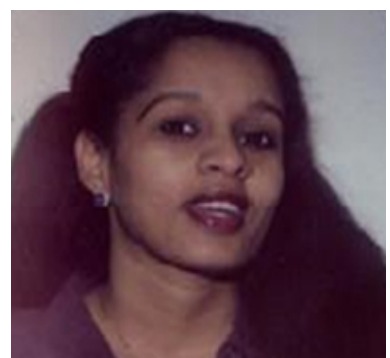

Ms. Muna Elobaid is an instructor and coordinator in the Department of Mathematics and Computer Science at the University of Maryland Eastern Shore. Originally from Sudan, she earned her MSc. in Computer Science from the University of Maryland Eastern Shore and is currently pursuing her Ph.D in leadership. She has published papers in referred journals and made scholarly presentations on such topics as ebooks, wireless communications, and currency exchange rates. A certified Microsoft Office Specialist, the courses she teaches include: Computer Concepts and Applications, Business Software Applications, and Office Technology and Records. 